\title{
E-LEARNING MANAGEMENT SYSTEMS: A FEATURE-BASED COMPARATIVE ANALYSIS
}

Saeed Salah http://orcid.org/0000-0002-4525-7825

Mahmoud Thabet http://orcid.org/0000-0002-0561-0276

Department of Computer Science, Al-Quds University, Jerusalem, Palestinian Territory

\begin{abstract}
One of the main important resources for higher education is a Learning Management System (LMS), which has shown an enhancement of students' progress with high quality learning outcomes worldwide. Many e-learning tools exist, each one has its own weaknesses and strongest points to the online learning process. This number increases continuously, and the existing tools are being updated, redeveloped, and upgraded. The aim of this study is to present a comprehensive comparative analysis between existing e-learning management systems. Unlike other relevant studies that have narrow scope either in terms of the number of tools or the number of comparative features, this work considers top twenty, highly recommended tools, both open source and commercial. Furthermore, more than twenty evaluation features were used carefully to fulfil students' and instructors' current needs. The results of this study have shown that Moodle outperforms the others and it is considered as the best free open source tool for educational purposes. It supports more than 100 different languages and provides its services to more than tens of millions of customers worldwide. Besides to Moodle, Chamilo, TotaraLearn, Open edX and Sakai have more built-in features that provide services to educational institutions. Also, this study showed that Docebo, SkyPrep, ProProfs, SAP Litmos, Moodle, TotaraLearn, Open edX and Opigno systems have more built-in security mechanisms such as antispam, antivirus, IP Blocker, data protection and complex password enforcement. Most considered systems have gamification features except Schoology, ATutor, Sakai, and Ilias, and most commercial systems can offer 24/7 customer care services, except Edmodo and Telnet, whereas open source tools offer this service on specific time slots except Opigno, Ilias, TotaraLearn, Chamilo, and Canvas where the service is offered 24/7.
\end{abstract}

Keywords: Learning Management System (LMS), E-learning, Open Source, Commercial, Moodle, Evaluation.

Manuscript first received: 2020-09-04. Manuscript accepted: 2021-02-25

Address for correspondence:

Saeed Salah, Department of Computer Science, Al-Quds University, Jerusalem, P.O. Box 20002,

Email: sasalah@staff.alquds.edu

Mahmoud Thabet, Department of Computer Science, Al-Quds University, Jerusalem, P.O. Box 20002,

Email: mahmoud.thabet@students.alquds.edu 


\section{INTRODUCTION}

One of the main important resources for higher education, especially universities, is a Learning Management System (LMS), which has shown an enhancement of students' progress with high quality learning outcomes worldwide (Oliveira, P.C., Cunha, C., \& Nakayama, M.K. (2015), Abdulaziz, A., Chowdhury, H., Kootsookos, A., Alam, F., Allhibi, A. (2019)). Some of the benefits of using the LMS are (i) it organizes the e-learning resources and content in one location; (ii) it provides a timely and unlimited access to courses' content; (iii) it easily tracks students' performance; (iv) it reduces the cost of learning and development processes; ( $v$ ) it reduces necessary time of learning and development; (vi) it quickly and conveniently expands, updates, and modifies e-learning courses; (vii) and some LMS tools have built in capabilities to integrate social learning experiences into the educational process (Kundi, G. M., Nawaz, A., \& Khan, S. (2010), Kulshrestha, T. \& Kant, A. (2013), Lopes, A. (2014)).

A LMS can be either commercial or open source that provides safe, reliable, and flexible e-learning environment. Its concept has been emerged directly from the e-learning paradigm that connects instructors and students in an interactive way to help in the reinforcement teaching process. Three types of learning methods exist: e-learning, distance learning and mobile learning. All these types use Internet resources to manage and administrate the educational process. Either using desktop, mobile devices, or cloud based services (Software-as-a-Service), the educational process should provide a timely and synchronous interaction between instructors and learners from everywhere (Han, I \& Shin, W. (2016), Capper, I. (2001), Grönlund, Å. \& Islam, Y. (2010), Kraleva, R., Kralev, V., Kostadinova, D. (2019)). Furthermore, some LMSs use machine learning concepts, automatic recognitions, social networking, and prediction of user preferences to automatically adapt their functionalities based on user requirements (Sheeba, T., \& Krishnan, R. (2019), Narayan, V., Herrington, J., \& Cochrane, T. (2019), Valova, I., \& Marinov, M. (2019)). Consequently, each LMS has its own ingredients, capabilities, and customizable modules. Examples of such models are course management, user management, communication facilities, student assessment, online examination, feedback administration, machine learning, and security, among others (Pankaja, N., \& Raj P. K., M. (2013), Deborah, J., Karthika, R., Vijayakumar, P., Bharat, R., \& Wang, Y. (2019)).

Currently, many open source and commercial LMS exist and available to the public, each one has its own strengths and weaknesses points to the online educational process. For this reason, it is important for a prospective customer to be well guided to make the best decision. Making the right choice while selecting an LMS is necessary because there are some systems that have unclear user terms, unnoticeable costs, unclear common features, and supported platforms, etc. This makes it necessary to make a comparative analysis among the common ones using important evaluation criteria. Furthermore, it is important to make a comparison study between LMS tools to select the suitable one and explore their strengths and limitations (Nadirah, N., Kasim, M., \& Khalid, F. (2016)).

This paper focuses on the comparison of top 20 highly recommended LMSs, both open source and commercial. These tools were selected carefully; a deep analysis and revision of scientific papers and professional Websites were conducted to facilitate the process of ranking the common LMSs (Refer to Table 1). The selected tools are Talent, Docebo, SkyPrep, ProProfs, Absorb, SAP Litmos, Edmodo, LearnUpon, iSpring Learn, Schoology, Moodle, Canvas, Chamilo, Totara Learn, Forma, ATutor, Open edX, Sakai, Opigno, and Ilias. More than twenty evaluation features were considered in this study. These features were selected based on the author long experience of working in higher educational institutions, as well as with the help of literature and official resources that 
care about the educational process's needs and requirements. These selected features are client, software deployment, platform, browser, mobile learning, SCORM complaint, multi-platform, customer support, communication methods, interface properties, collaborative learning, gamification, reporting, management methods, user roles, access management, client authentication, certificate management, compliance management, and security. To ease the comparative analysis, we suggested a new classification of the selected set of features based on three categories: supported platform, common features, and administration and management (See Figure 1).

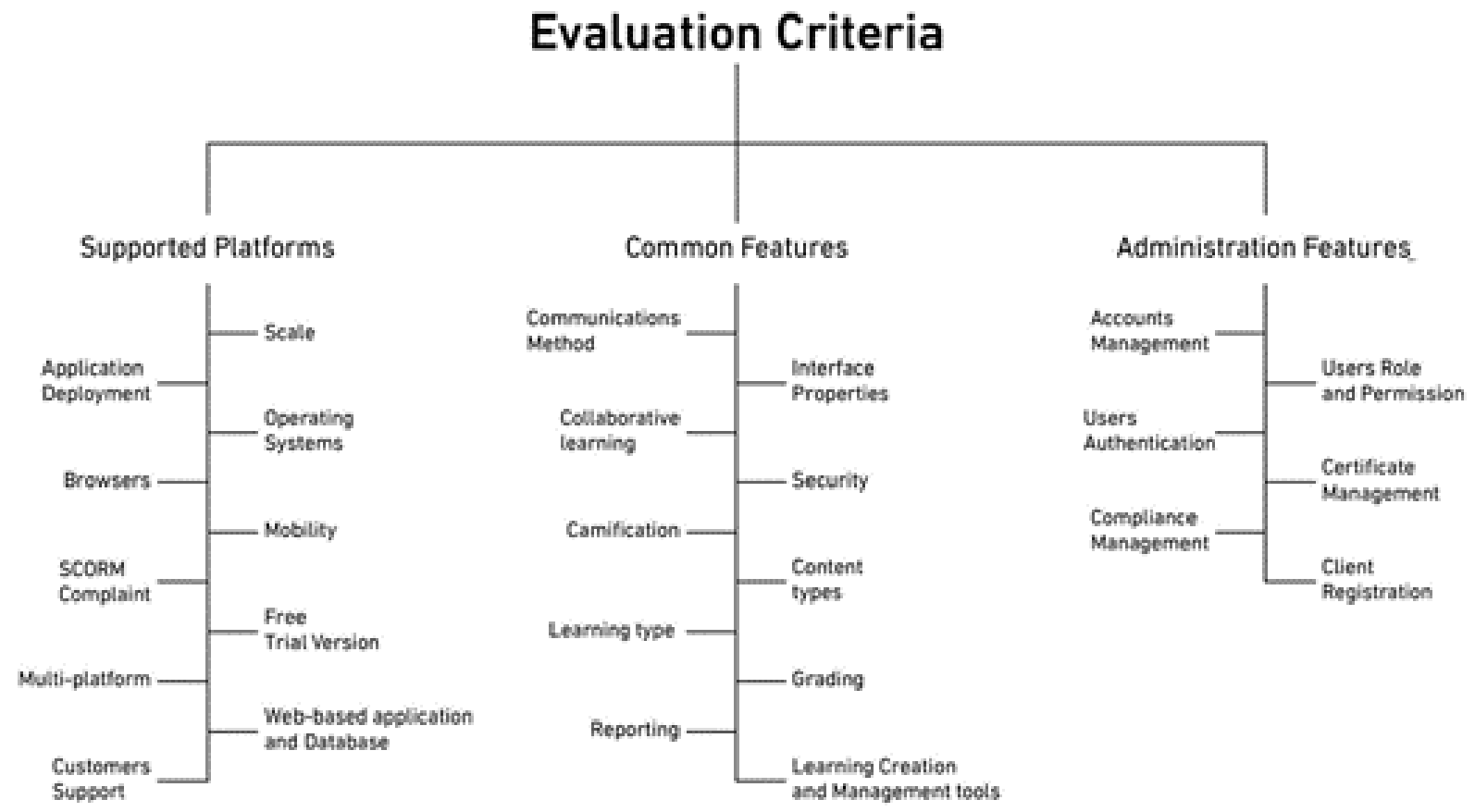

Figure 1. The classification of e-learning features taken as evaluation criteria.

Besides the introduction section, this paper contains the following sections. A review of the related work is presented in Section 2. Section 3 gives some technical information about the selected LMSs and the suggested evaluation criteria. The comparative tables along with their discussions are presented in Section 4. Finally, in Section 5, we conclude this research work and shed light to some future works.

\section{RELATED WORK}

During the past few years, several comparative studies were proposed to analyze the performance of existing LMSs against sets of features. In this section, we summarize the most relevant works. The research carried out by Fertalj, K., Jerkovic, H., \& Hlupic, N. (2006) made a comparative study of 10 LMSs using a set of features. They focused on LMSs with proprietary, open source, mainly proprietary and partly standard, mainly standard, and partly proprietary. They made the comparative analysis based on several features such as discussion forum, course management, file exchange, 
student tracking, automated testing and scoring, online grading, internal email, authentication, and instructional design tools, among others. This study showed that ANGEL 6.2 belonging to the category standard/proprietary type, outperforms the others with the highest score - approximately $92.6 \%$. Then, comes the Blackboard academic suite which belongs to the same category with a score approximately $74.5 \%$. They also argued that standard/proprietary systems lead electronic-learning market at current time, also they will be moving forward during the coming years.

A similar research was carried out by Erdenebaatar, A., Zolboo, D., \& Baigaltugs, S. (2011). The authors provided a comparative analysis of 3 LMSs - Atutor, Blackboard and Moodle - using 8 features. These fetaures are communication, productivity, participation, teacher, course delivery, HW/SW, and pricing and licensing. They concluded that Moodle has the best widspread usage and populrity among the educational community due to its affordability by more than a hunderd supported languages, cost reduction, and built-in security mecahnims. The same work was conducted by Cavus, N., \& Zabadi, T. (2014). But, besides the Moodle, the authors seleced another 5 more open source LMSs to compare with - ATutor, Claroline, Dokeos, Ilias, and Sakai. The set of selected features were related to whiteboard and video services, discussion forums, file exchange, internal mail, online journal mail, and real live chat features. This study showed that Moodle is the best choice when considering whiteboard features and active discussion forums. It also available for real time synchronous discussion with user friendly interface.

Dobre, I. (2015) classified the existing LMSs into four categories: proprietary, open source, cloud-based, and hybrid LMS. This study argued that popularity of open source LMSs will increase by $20.1 \%$ when using Moodle, while $13.1 \%$ when using Blackboard. Also, this study showed that cloud based LMS became a promising choice, especially for enterprises that want to get over of installing, managing, and securing these services by their own.

Poulovaa, P., Simonovaa, I., \& Manenovab, M. (2015) analyzed 4 LMSs - Claroline, Moodle, Blackboard, and Enterprise Knowledge Platform TM - using several evaluation criteria like price, course management, communication, blogs, survey, workshop, and virtual classroom, among others. The outcome of this study showed that both Claroline and Moodle are freely available, while Blackboard and EKP are commercial with prices depending on the number of users and the required set of features. Also, according to this study, $80 \%$ of the built-in tools are identical in both Blackboard and EKP, and this number is higher compared to Claroline which contains fewer tools. The communication tools were included in all four LMSs.

Moodle 2.0 and Blackboard 9.1 were compared by Subramanian, P., Zainuddin, N., \& Alatawi, S. (2014). They made the comparison based on 3 categories of features: communication tools (discussion forum, file exchange, email notification, notifications and dashboard), productivity tools (calendar, progress review and searching) and student involvement tools (group organizing, community networking, course menu, assignments, custom grading, and grading preferences). The main conclusion of this work is that Moodle is the best choice when considering the above categories.

Ajlan, S. (2012) provided a comparative analysis of 10 LMSs, both open source and commercial. He first categorized the selected features into 3 categories with 40 features. The suggested categories are learner tools that include communication, productivity, and student involvement; support tools 
that include administration, course delivery, and curriculum design; and technical specifications that include HW/SW and pricing/licensing. The outcome of this study showed that Moodle 1.8 comes first with 38 out of 40 built-in features and capabilities, Desire2Learn 8.1, ANGEL Suite 7.1 and Sakai 2.3 come next with 37 features and capabilities. LON-CAPA comes at the end with 30 features.

Kraleva, R., Sabani, M., \& Kralev, V. (2019) provided a comparative analysis of 36 LMS using learning skills tools that contain the following features: SCORM compliant, material, assignments, gamification, evaluation; communication tools (chat, forums and mail messages); and productivity tools (uploading/downloading, analysis of students' achievement, security, and Web-based technology, among others). According to this study, all the considered LMSs support the use of multimedia elements, creating and editing lectures and making exercises and course assignments. Only $86 \%$ of the studied systems meet the SCORM standard, and $46 \%$ and $68 \%$ provide chat and forum supports, respectively.

In summary, the aim of this work is to present a comprehensive comparative study of common existing e-learning management systems. Unlike other relevant studies that have narrow scope either in terms of the number of tools or the number of comparative features, this work considers top twenty, most deployment tools, 10 tools were selected from the private sectors, and the other 10 were selected from the freely available software with GPL. Furthermore, more than twenty evaluation criteria were used in this comparative study. To ease the comparative analysis, we divided these features into a newly suggested classification having three categories of features. These categories are: supported platform; features belonging to this category are related to system support features from a general perspective, common features; features belonging to this category are mainly related to internal operational features and activities supported by the tool, and administration and management features; features belonging to this category are related to system management and administration, both for users and courses (See Figure 1).

\section{SELECTED LMSS AND EVALUATION CRITERIA}

After reviewing a considerable amount of scientific and Web-based resources, we were able to select the top highly recommended LMSs. Table 1 provides some technical information about the selected LMSs. As shown in the table, the first 10 tools are commercial and the other 10 are open source with GPL license. The selection of these tools was based upon several criteria. Among the most ones are the number and type of customers, supported languages, and customers' feedback. Also, the analysis being carried out in this study was based upon the latest version update as declared on the tool's main Website. The information presented in the table are taken from the main tools' Websites and other relevant resources.As shown in Figure 1, we suggested a new classification of the selected set of features into three main categories as follows:

\section{Supported platform}

I.1. Scale: Small, medium, large enterprises.

I.2. Application deployment: mobile, desktop, cloud based (SaaS).

I.3. Operating System: Linux, Mac, Android, iOS Windows.

I.4. Supported Browser: Safari, Chrome, Opera, Explorer, Firefox.

I.5. Mobility support: Offline/online. 


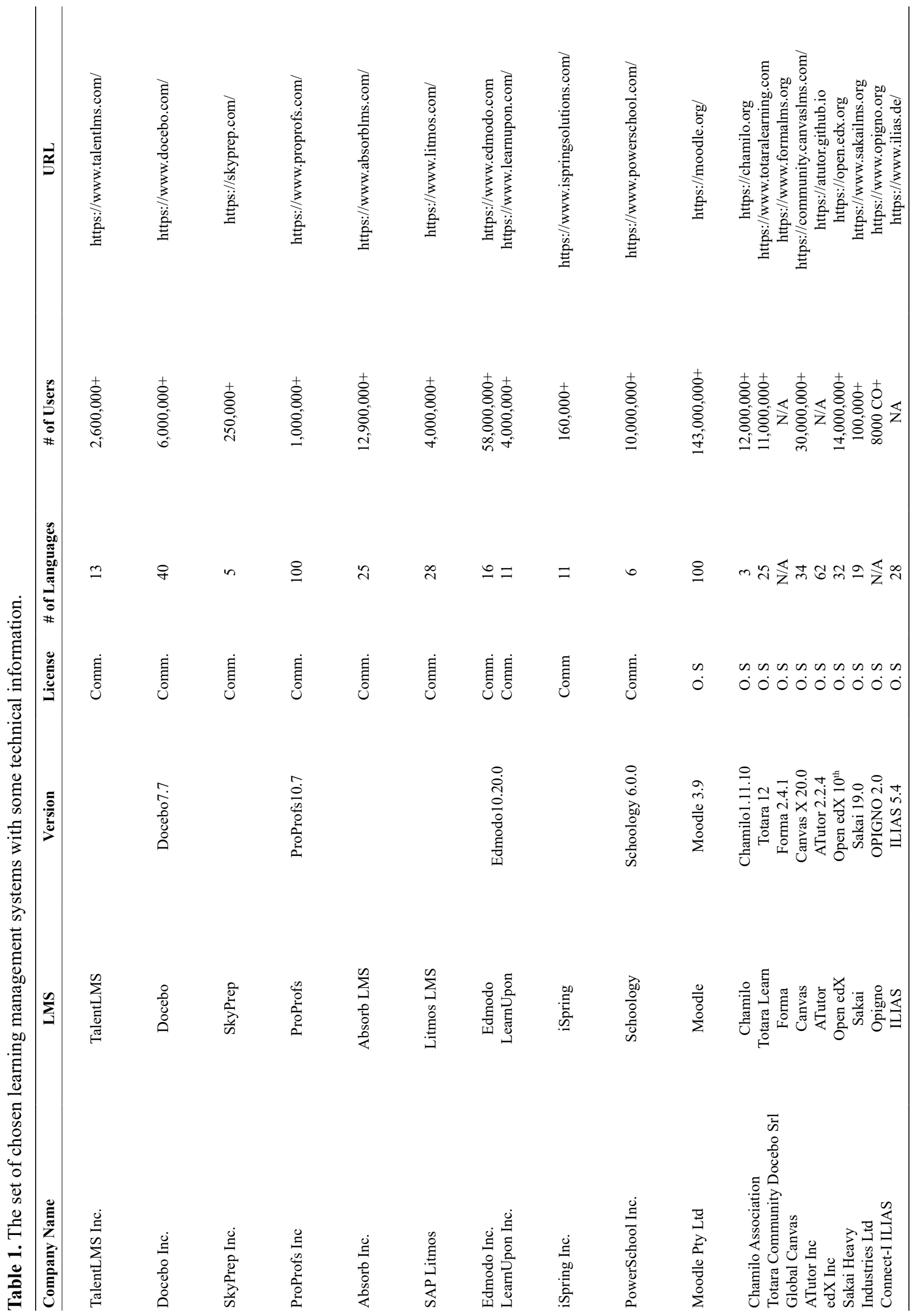


I.6. SCORM complaint: (4 ${ }^{\text {th }}$ Edition).

I.7. License: Freely available or commercial with free trial.

I.8. Multi-platform support.

I.9. Web-based and database.

I.10. Customer support: 24/7, Specific Hours (SHs).

\section{Common features}

II.1. Communication methods: File sharing and management (A1), forum discussion (A2), online chat (A3), live events (A4), email and notification (A5).

II.2. Interface properties: multilingual (B1), calendar (B2), dashboard (B3), language feature (B4), manage block (B5), add External page (B6), location feature (B7), and media feature (B8).

II.3. Collaborative learning: assignments (C1), feedback (C2), quiz (C3), workshop (C4).

II.4. Security: anti-spam (D1), data protection (D2), antivirus (D3), IP blocker (D4), and complex password enforcement (D5).

II.5. Gamification: Badges (E1), leaderboards (E2), levels (E3), points (E4), and rewards (E5).

II.6. Content type: Documentation (F1), online lessons (F2), online seminars (F3), and video conferencing (F4).

II.7. Learning type: Learning by teachers (G1), learning by-self (G2), blend learning (G3), and virtual study room $(\mathrm{G} 4)$.

II.8. Grading: Gradebook (H1), assessments (H2), gradebook remarks (H3), and manual grading (H4).

II.9. Reporting: Auto-report (I1), dashboard reports (I2), custom report (I3), email delivery of reports (I4), mark report (I5), report formats (I6), and live Logs (I7).

II.10. Learning creation and management tools: eLearning course creation tool (J1), upload courses (J2), course backup (J3), survey engine (J4), learning Paths (J5), supported files $\mathrm{PPT} / \mathrm{PDF} /$ Videos (J6), assignment creation (J7), course activity - add, delete and sort (J8), course template (J9), course enrolment (J10).

\section{Management and administrative features}

III.1. Account management: Add new account (K1), archive clients (K2), users' group search (K3), user filtering (K4), user profile (K5), user management information (K6)

III.2. User role and permission: Create role (L1), permission role (L2), assignment permission (L3).

III.3. User authentication: LDAP (M1), custom user login page (M2), manual account (M3), Not have ability to login user's account (M4), self-registration (M5), self- registration with admin confirmation instead of user confirmation (M6). 
III.4. Certificate management: Manage certification templates (N1), predefined certification templates (N2), unique Certificate by course (N3), unique certification by curriculum (N4).

III.5. Compliance management: Certificate expiration notifications (O1), manage certification expiration (O2) and due date notification email (O3).

III.6. Client registration: Online attendance tracking (P1), auto-registration (P2), guest access features (P3) and manual and self-registration (P4).

\section{COMPARISON RESULTS AND DISCUSSION}

The comparative results are shown in Tables 2, 3, 4 and 5. Table 2 summarizes the main differences between the 20 tools in terms of features belonging to category 1 (supported platform); Tables $3 \& 4$ detail the comparative summary of features belonging to category 2 (common features); and finally, the results belonging to category 3 (administration and management) are summarized in Table 5.

It is worth mentioning that when referring to the tables below, for limited space and page margin settings, we assigned labels to features, e.g., forum discussion (A2), video conferencing (F4), etc. (Refer to Section 3).

Referring to Table 2, we extract the following findings: (i) there is no optimal system that offers all-in-one package to the online educational process, but the best system is the system that adapt its features and capabilities to meet users' emergent needs; (ii) we also noticed that, contrary to commercial systems, the high volume of customers who use open source systems came from educational institutions, such systems like Moodle, Chamilo, Totara Learn, Open edX, and Sakai; (iii) All tools support small to large enterprises, except Canvas which is mainly designed to support small enterprises. Regarding the HW/SW supported platform, we observed the followings: (i) all common operating systems (Windows, Linux, Mac, iOS, and Andriod), and Web browsers (Internet Explorer, Firefox, Google Chrome, and Safari) are supported by all tools, except Edmodo, Schoology and Sakai that do not support Linux, and ATutor does not support mobile platform; (ii) it is also noticed that most commercial tools provide $24 / 7$ customer care services, except Talent, Edmodo, and the following open source tools Canvas, Chamilo, Totara Learn, Opigno, and Ilias provide 24/7 customer care services; (iii) some tools' developers provide free trial versions, except Edmodo, Schoology, Totara Learn, Forma, Open edX, Opigno and Ilias, and support mobility, SCORM complaint v4.0 and SaaS.

Category 2 results (common features) are represented in Tables $3 \& 4$. We derive the following findings: (i) some tools have discussion forums, except Ilias, and online chart features, except Docebo, SkyPrep, Schoology, iSpring, ATutor, Sakai, and Ilias (ii) live activities exist in all tools, except Schoology, Chamilo, ATutor, Sakai, and Ilias. Regarding security features, we observed that Docebo, SkyPrep, ProProfs, SAP Litmos, Moodle, Totara Learn, Open edX and Opigno systems have more secured features such as anti-spam, antivirus IP-Blocker, data protection, and complex password enforcement; (iii) finally, most tools have gamification features, except Schoology, ATutor, Sakai, and Ilias. 







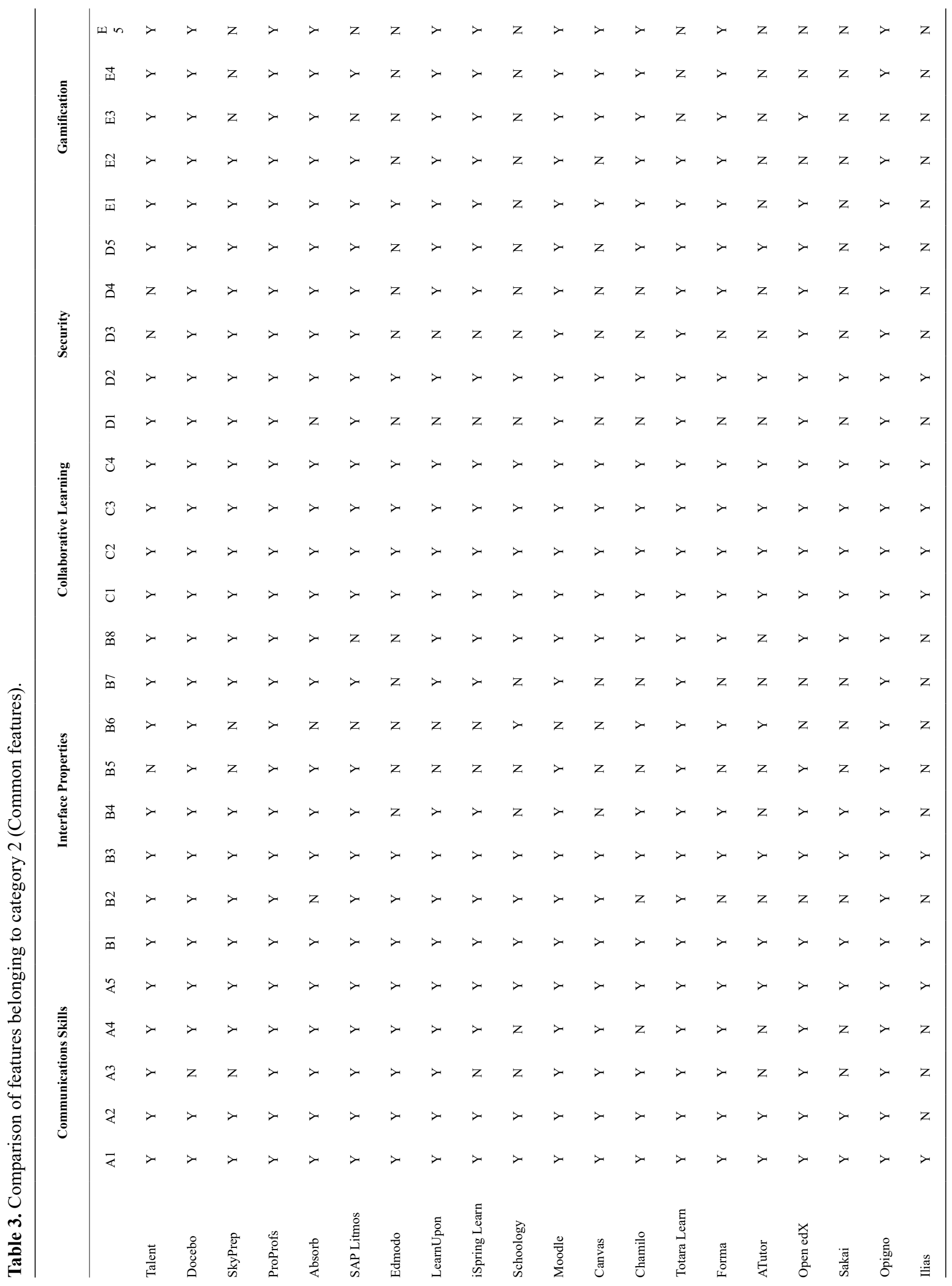




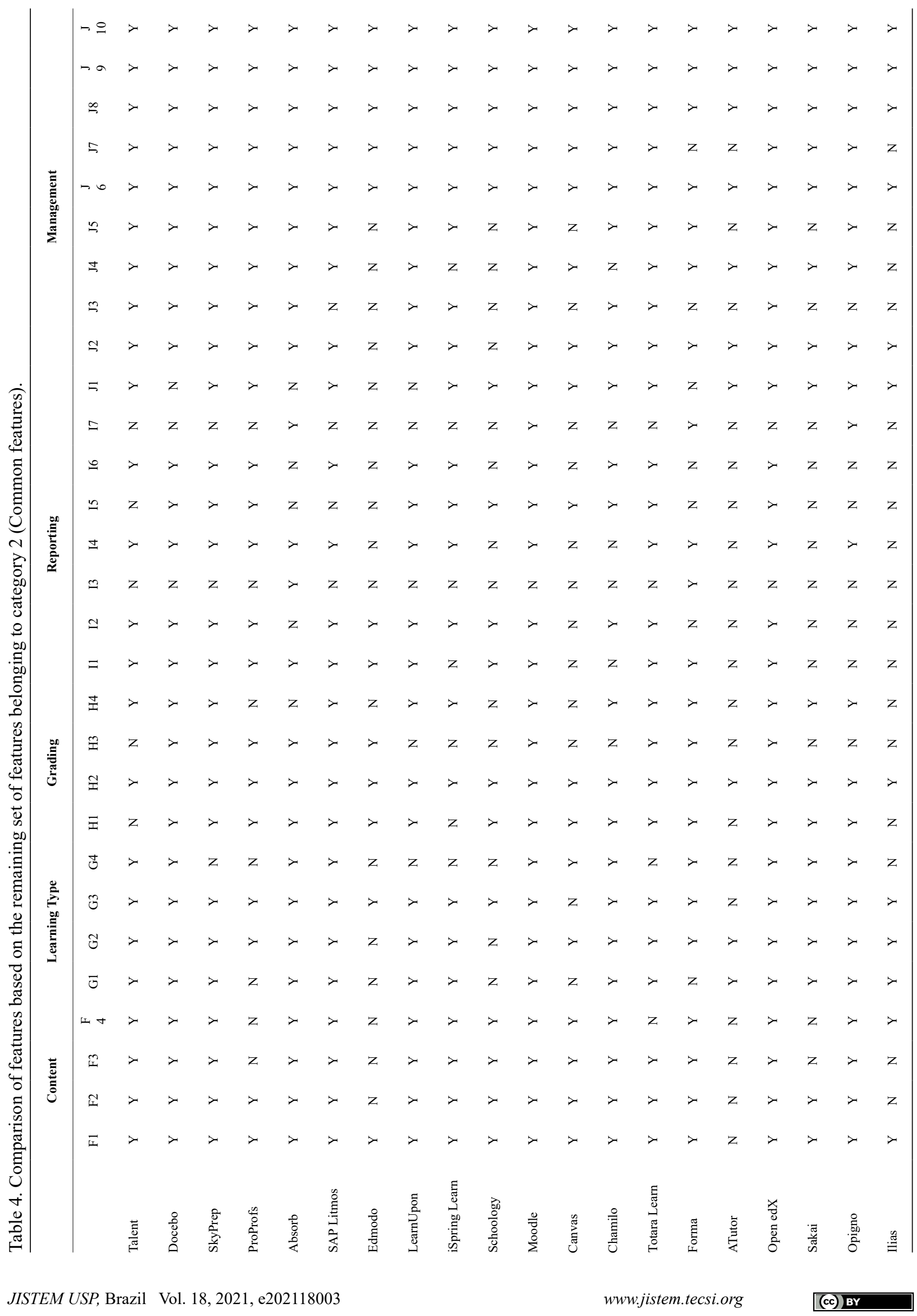




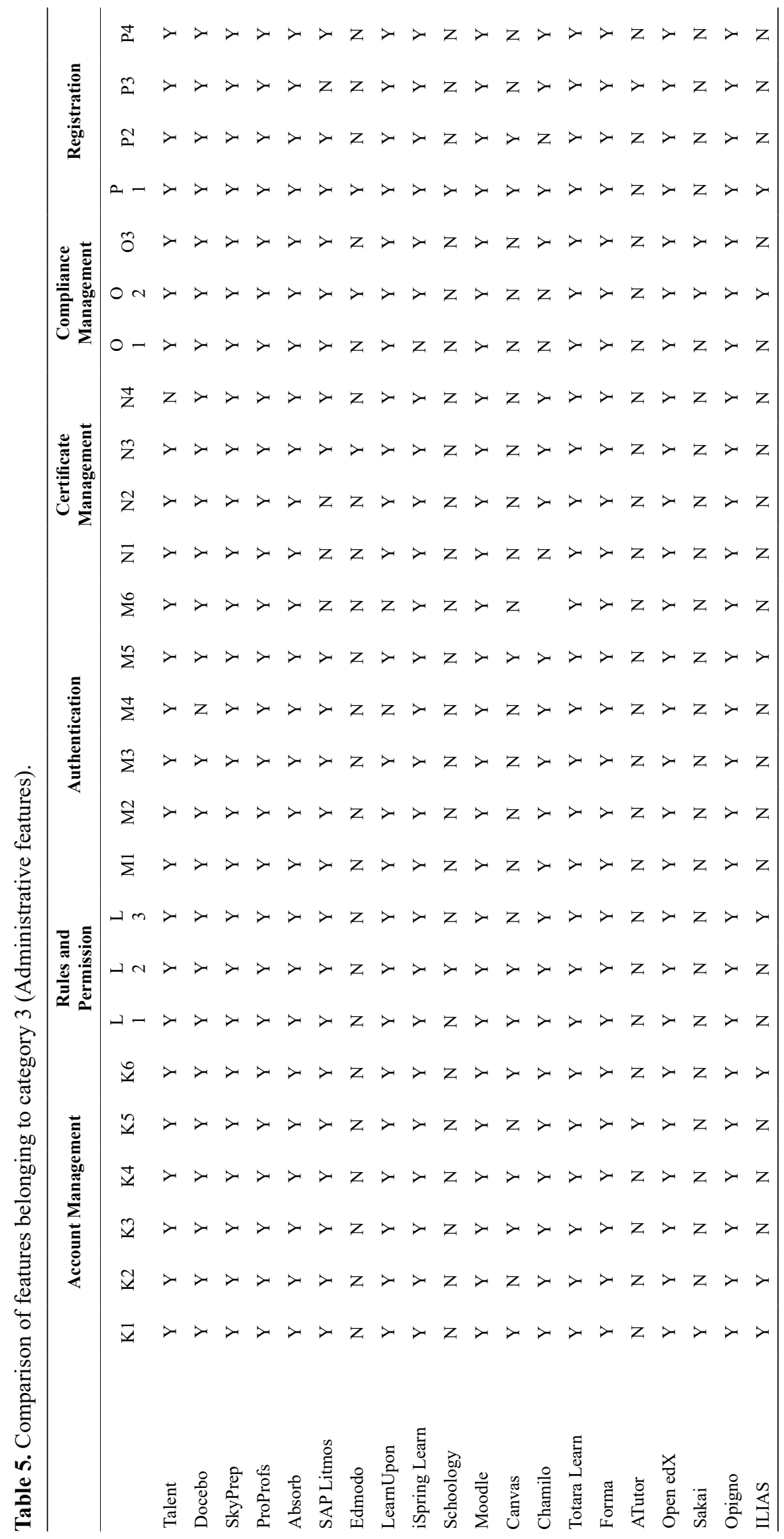


Referring to Table 4; (v) most tools support various content type such as documentation, online lessons, online seminars, video conferencing, and support various learning type - learning by teachers, learning by-self, blend learning and virtual study room, except ProProfs, Edmodo, Schoology, Canvas, and Forma that do not support learning by teachers, Edmodo and Schoology do not support learning by-self. Whereas Canvas and ATutor do not support blended Learning, and all tools support grading, except Ilias and ATutor. (vi) ATutor, Sakai, and Ilias do not support creating reports; Forma, ATutor, and Ilias do not have features to support assignment creation, and course uploading is not supported by Edmodo and Schoology, course backup is not supported by SAP Litmos, Edmodo, Schoology, Canvas, Forma, ATutor, Sakai, Opigno, and Ilias; (vii) and finally, we observed that all tools accept common file formats such as PPT, PDF, JPEG and Video.

From Table 5 which summarizes the comparative analysis of features belonging to category 3 (management and administration), we conclude the following: (i) all tools have auto-registration features, except Edmodo, Schoology, Chamilo, ATutor, Sakai, and Ilias; (ii) certificate management is supported by all tools, except Schoology, Canvas, ATutor, Sakai, and Ilias; (iii) the prices of commercial tools depend on the number of users and the required set of features; (iv) Moodle and ProProfs support more than 100 different languages, and Moodle provides services to more than 143,000,000 users around the world; (v) and finally, Moodle, Chamilo, TotaraLearn, Open edX, and Sakai are specialized for providing services to educational institutions more than others.

\section{CONCLUSION AND FUTURE WORK}

This paper presented an updated feature-based comparative analysis of highly recommended LMSs, both commercial and open source. More than twenty evaluation criteria were used to conduct this comparative study. The results have shown that there is no optimal LMS that offers all-in-one package to the online educational process, but the best system is the system that adapt its features and capabilities to meet users' evolving needs. For most of the tested features, Moodle remains on the top, and it is considered as the best free open source tools and provides its services to more than hundreds of millions of customers worldwide. Besides to Moodle, Chamilo, TotaraLearn, Open edX and Sakai have more built-in features that provide services to educational institutions more than others. Also, this study showed that Docebo, SkyPrep, ProProfs, SAP Litmos, Moodle, Totara Learn, Open edX and Opigno systems have more built-in security mechanisms such as antispam, antivirus, IP Blocker, data protection and complex password enforcement. Most considered systems have gamification features except Schoology, ATutor, Sakai, and Ilias, and they can offer 24/7 customer care services, except Edmodo and Telnet, whereas open source tools offer this service on specific time slots, except Opigno, Ilias, TotaraLearn, Chamilo, and Canvas, where the service is offered 24/7.

As a future work, we will analyze the performance of LMSs using customers' feedback. For this purpose, we will apply the common machine learning methods being implemented for sentiment analysis domain to analyze customers' opinions about these tools, and to build classification models for the optimal set of learning features. 


\section{REFERENCES}

Oliveira, P.C., Cunha, C., \& Nakayama, M.K. (2015). Learning Management Systems (LMS) and e-learning management: an integrative review and research agenda. Jistem Journal of Information Systems and Technology Management, 13, 157-180.

Abdulaziz, A., Chowdhury, H., Kootsookos, A., Alam, F., Allhibi, A. (2019). Utilization of learning management systems (LMSs) in higher education system: A case review for Saudi Arabia, International Conference on Energy and Power, ICEP2018, 13-15.

Kundi, G. M., Nawaz, A., \& Khan, S. (2010). The predictors of success for e-learning in higher education institutions (HEIs) in N-W.F.P, Pakistan. Journal of Information Systems \& Technology Management, 7(3), 545+.

Kulshrestha, T. \& Kant, A. (2013). Benefits of learning management system (LMS) in Indian education, International Journal of Computer Science \& Engineering Technology (IJCSET), 4(8).

Lopes, A. (2014). Learning management system in higher education, In Proceedings of EDULEARN14 Conference, $7^{\text {th }}$ to $9^{\text {th }}$ July 2014, 5360-5365, Barcelona, Spain.

Han, I \& Shin, W. (2016). The use of a mobile learning management system and academic achievement of online students, Computers \& Education, 102, 79-89.

Capper, I. (2001). E-learning growth and promise for the developing world, TechKnowLogia, 2(2), 7-10.

Grönlund, Å. \& Islam, Y. (2010. A mobile e-learning environment for developing countries: The Bangladesh virtual interactive classroom, Information Technology for Development, 16(4), 244259.

Kraleva, R., Kralev, V., Kostadinova, D. (2019). A methodology for the analysis of block-based programming languages appropriate for children, Journal of Computing Science and Engineering, 13(1), 1-10.

Sheeba, T., \& Krishnan, R. (2019). Automatic detection of students learning style in learning management system, In Proc. of the Smart Technologies and Innovation for a Sustainable Future, Springer, 45-53.

Narayan, V., Herrington, J., \& Cochrane, T. (2019). Design principles for heutagogical learning: Implementing student-determined learning with mobile and social media tools, Australasian Journal of Educational Technology, 35(3), 86-101.

Valova, I., \& Marinov, M. (2019). Facebook as a tool aiding university education-whether it is possible and useful, TEM Journal, 8(2), 670-676.

Pankaja, N., \& Raj P. K., M. (2013). Proprietary software versus open source software for Education, American Journal of Engineering Research (AJER), 2 (7), 124-130.

Deborah, J., Karthika, R., Vijayakumar, P., Bharat, R., \& Wang, Y. (2019). Secure online examination system for e-learning, IEEE Canadian Conference of Electrical and Computer Engineering (CCECE), Edmonton, AB, Canada, 1-4, doi: 10.1109/CCECE43985.2019.9052408. 
Nadirah, N., Kasim, M., \& Khalid, F. (2016). Choosing the right learning management system (LMS) for the Higher Education Institution Context: A Systematic Review. International Journal of Emerging Technologies in Learning (iJET), 11(6).

Fertalj, K., Jerkovic, H., \& Hlupic, N. (2007). Comparison of e-Learning Management Systems. In Proceedings of the $5^{\text {th }}$ WSEAS International Conference on E-Activities, Venice: WSEAS, 189-194.

Erdenebaatar, A., Zolboo, D., \& Baigaltugs, S. (2011). Comparison of the learning management systems. International Conference EICHTE-2011, Ulaanbaatar, Mongolia, 1, 2011.

Cavus, N., \& Zabadi, T. (2014). A comparison of open source learning management systems, Procedia - Social and Behavioral Sciences, Elsevier, 143, 521-526.

Dobre, I. (2015). Learning management systems for higher education- an overview of available options for Higher Education Organizations, Procedia - Social and Behavioral Sciences, Elsevier, 180, 313-320.

Poulovaa, P., Simonovaa, I., \& Manenovab, M. (2015). Which one or another? Comparative analysis of selected LMS, Procedia - Social and Behavioral Sciences, Elsevier, 186, 1302-1308.

Subramanian, P., Zainuddin, N., \& Alatawi, S. (2014). A study of comparison between Moodle and Blackboard based on case studies for better LMS, Journal of Information Systems Research and Innovation, 2014.

Al-Ajlan, S. (2012). A comparative study between e-learning features. In Tech, 332, 03-Feb2012.

Kraleva, R., Sabani, M., \& Kralev, V. (2019). An analysis of some learning management systems, International Journal on Advanced Science Engineering Information Technology, 9(4), 1190-1198. 